\title{
Exceptional oxygen barrier performance of pullulan nanocomposites with ultra-low loading of graphene oxide
}

\author{
Ilke Uysal Unalan ${ }^{1,2}$, Chaoying Wan $^{2}$, Łukasz Figiel ${ }^{2}$, Richard T. Olsson ${ }^{3}$, Silvia Trabattoni ${ }^{4}$, \\ Stefano Farris ${ }^{1}$
}

${ }^{1}$ DeFENS, Department of Food, Environmental and Nutritional Sciences-Packaging Division, University of Milan, via Celoria 2 - 20133 Milan, Italy

${ }^{2}$ International Institute for Nanocomposites Manufacturing, WMG, University of Warwick, Coventry, CV4 7AL, UK
${ }^{3}$ KTH-Royal Institute of Technology, School of Chemical Science and Engineering, Fibre and Polymer Technology, Teknikringen 56, 10044 Stockholm, Sweden

${ }^{4}$ Department of Materials Science, University of Milano Bicocca, via Cozzi 55 - 20125 Milan, Italy

\footnotetext{
Corresponding author (S. Farris). Tel.: +39 0250316654; Fax: +39 0250316672

Email address: stefano.farris@unimi.it
} 


\begin{abstract}
Polymer nanocomposites are increasingly important in food packaging sectors. Biopolymer pullulan is promising in manufacturing packaging films or coatings due to its excellent optical clarity, mechanical strength, and high water-solubility as compared to other biopolymers. This work aims to enhance its oxygen barrier properties and overcome its intrinsic brittleness by utilizing 2D planar graphene oxide (GO) nanoplatelets. It has been found that the addition of only $0.2 \mathrm{wt} \%$ of GO enhanced the tensile strength, Young's modulus, and elongation at break of pullulan films by about 40,44 and $52 \%$, respectively. The light transmittance at $550 \mathrm{~nm}$ of the pullulan/GO films was $92.3 \%$ and haze values were within 3.0\% threshold, which meets the general requirement for food packaging materials. In particular, the oxygen permeability coefficient of pullulan was reduced from 6337 to $2614 \mathrm{~mL} \mu \mathrm{m} \mathrm{m}^{-2}\left(24 \mathrm{~h}^{-1}\right) \mathrm{atm}^{-1}$ with as low as $0.05 \mathrm{wt} \%$ of GO loading and further to $1357 \mathrm{~mL} \mu \mathrm{m}$ $\mathrm{m}^{-2}\left(24 \mathrm{~h}^{-1}\right) \mathrm{atm}^{-1}$ when GO concentration reached $0.3 \mathrm{wt} \%$. The simultaneous improvement of the mechanical and oxygen barrier properties of pullulan was ascribed to the homogeneous distribution and prevalent unidirectional alignment of GO nanosheets, as determined from the characterisation and theoretical modelling results. The exceptional oxygen barrier properties of pullulan/GO nanocomposites with enhanced mechanical flexibility and good optical clarity will add new values to high performance food packaging materials.
\end{abstract}

Keywords: biopolymer, food packaging, graphene oxide, mechanical properties, oxygen permeability. 


\section{Introduction}

The development of cost-effective and high performance materials offering low gas permeability, high transparency, and enhanced mechanical stability is highly sought-after in food packaging applications. The generation of nanocomposite biopolymer materials fulfilling these requirements is challenging but at the same time opens new possibilities toward "greener" packaging structures from biopolymers with same or even better overall performance compared to the conventional materials [1]. A key aspect for the preparation of these novel materials is the enhancement of the interfacial compatibility between the filler phase and the surrounding polymer matrix, promoting the dispersion and the exfoliation of plate-like fillers that may provide lower gas permeability and bi-axial reinforcement in film materials.

Among many natural inorganic plate-like fillers (e.g., clays), the synthetic graphene oxides are rapidly finding novel applications. Graphene oxide (GO) is a quasi-two-dimensional honeycomb lattice carbon material with oxygen-containing functional groups attached on the basal planes and edges, such as hydroxyl, epoxide, carbonyl and carboxyl groups [2]. These functionalities significantly alter the van der Waals interactions between the layers of graphene and provide them with desirable solubility in water and polar organic solvents [3]. The polar functional groups on the GO surface also promote interfacial interactions with polar polymers, such as hydrophilic biopolymers. In addition, its high elastic modulus, excellent thermal properties, large aspect ratio, and distinctive two-dimensional structure make GO a promising alternative to the many inorganic clays for the next generation of bionanocomposites with high mechanical [4-7], thermal [7, 8], and gas barrier properties against $\mathrm{O}_{2}[6,9-11], \mathrm{N}_{2}[10]$, and water vapour $[9,12]$ for food packaging applications. Not less important, monolayer-GO offers better optical clarity than widely used clays [6, $11]$.

The combination of GO with biopolymers is therefore one of the most promising strategies toward high performance bionanocomposites to replace traditional packaging materials (e.g., oilbased plastics) without impairing the goal of extending shelf life, as a result of low gas permeability $[13,14]$. 
The aim of this study is to assess the effects of GO on the properties of pullulan, in the form of film materials for food packaging applications. Pullulan is a non-ionic exopolysaccharide obtained from the fermentation medium of the fungus-like yeast Aureobasidium pullulans [15]. Its chemical formula has been suggested as $\left(\mathrm{C}_{6} \mathrm{H}_{10} \mathrm{O}_{5}\right)_{n}[16]$, and its chemical structure is viewed as a maltotriose trimer given by the succession of $\alpha-(1 \rightarrow 6)$-linked $(1 \rightarrow 4)-\alpha$-D-triglucosides [17]. Pullulan is water soluble, odourless, tasteless, nontoxic, and biodegradable, with good adhesive and binding properties [17]. Pullulan is currently used in the pharmaceutical sector for the manufacturing of hard and soft capsules; in the biomedical field for gene delivery, targeted drug therapy, tissue engineering, wound healing, and in diagnostic applications; and in the area of food industry as a thickening, stabilizing, texturizing, and gelling agent. Pullulan is also being used in the cosmetics (lotions, shampoos, facial masques) and oral care (toothpaste, denture adhesive) sectors. More recent uses of pullulan include photographic, lithographic, optic, and electronic applications [13].

The increasing interest toward this polymer specifically for food packaging applications mainly lies in the extensive hydroxyl groups on its backbone, high chain flexibility around the $\alpha-(1 \rightarrow 6)$ linkage, superior clarity over most biopolymers as well as high oxygen barrier properties under dry conditions [18]. To the best of our knowledge, this is the first work that demonstrates the use of GOmodified pullulan as a bulk biopolymer for bionanocomposite applications. Both the measured oxygen permeability and elastic modulus were compared with predictive models with the goal of clarifying the physical GO arrangement of the newly generated biopolymer nanocomposites.

\section{Experimental}

\subsection{Materials}

Pullulan (PF-20 grade, Mw 200 000 DA) was obtained from Hayashibara Biochemical Laboratories Inc., Okayama, Japan. Graphene flakes were purchased from Sigma Aldrich, UK. Hydrogen peroxide aqueous solution $\left(\mathrm{H}_{2} \mathrm{O}_{2}, 20-35 \mathrm{wt} \%\right)$, hydrochloric acid $(\mathrm{HCl})$, potassium permanganate $\left(\mathrm{KMnO}_{4}\right.$, > $95 \mathrm{wt} \%)$, sodium nitrate $\left(\mathrm{NaNO}_{3},>95 \mathrm{wt} \%\right)$, and sulfuric acid $\left(\mathrm{H}_{2} \mathrm{SO}_{4},>95 \mathrm{wt} \%\right)$ were all analytical grade and purchased from Fisher Scientific, UK. 


\subsection{Characterisation}

Atomic Force Microscopy (AFM) experiments were carried out with the goal of gathering information about surface morphology and the degree of exfoliation of GO. Measurements were conducted in intermittent-contact mode with a Nanoscope V Multimode (Bruker, Germany) on diluted GO water dispersion $(0.02 \mathrm{mg} / \mathrm{mL})$ by the deposition of $10 \mu \mathrm{L}$ onto mica substrate. The images were collected with a resolution of $512 \times 512$ pixels with silicon tips (force constant $40 \mathrm{~N} / \mathrm{m}$, resonance frequency $300 \mathrm{kHz}$ ). The analyses performed on the acquired images were conducted with Nanoscope software (version 7.30). The mean values reported for GO sheet dimensions were calculated over ten images.

A transmission electron microscope (TEM) (JEOL 2000FX) at an operating voltage of $200 \mathrm{kV}$ was used for the analysis of the GO morphology. Digital images were captured with a GATAN ORIUS 11 megapixel digital camera. Samples for TEM analyses were prepared by drop-casting a few millilitres of GO water dispersion after ultrasonication onto holey carbon grids and letting the samples rest for 24 hours at room temperature to allow water evaporation. 
Scanning electron microscopy (SEM) micrographs were obtained to acquire more detailed information on the degree of stacking of GO-loaded pullulan films. Cross sections were examined on a LEO 1430 (Carl Zeiss, Oberkochen, Germany) operating at $20 \mathrm{kV}$ and $3 \times 10^{-3}$ Torr, SEI detection mode. Cross-sectioned specimens were obtained blazing a trail on dried (i.e., kept in a desiccator for at least two weeks) film samples by gently using a scalpel. The so produced 'track' served as a guide for the successive rupture of the film made by hands. Before analysis, samples were sputter-coated with gold to a thickness of approximately $10 \mathrm{~nm}$ using a Semprep 2 sputter coater (Nanotech Ltd., Prestwick, UK) at $10 \mathrm{~mA}$.

Qualitative information on the oxidation of pristine graphene was firstly assessed by infrared spectroscopy using a PerkinElmer FT-IR Spectrum 100 Series spectrometer (PerkinElmer, Waltham, MA) equipped with a universal attenuated total reflectance (UATR) accessory featuring a singlereflection sampling plate with a $1.8 \mathrm{~mm}$ round germanium surface. The spectra were recorded on GO powder over a range of $600-4000 \mathrm{~cm}^{-1}$ with a resolution of $4 \mathrm{~cm}^{-1}$ and averaged over 10 scans. Spectrum 6.0 software was used for data acquisition and analysis.

X-ray photoelectron spectroscopy (XPS) measurements were also performed to acquire quantitative information on the atomic composition of the graphene surface after oxidation. Analyses were performed in an XM1000 instrument (Omicron NanoTechnology GmbH, Germany) equipped with a monochromatic $\mathrm{Al} \mathrm{K} \alpha$ source. Data analysis was carried out using the CasaXPS package, using Shirley backgrounds, mixed Gaussian-Lorentzian (Voigt) line shapes and asymmetry parameters for the $\mathrm{sp}^{2}$ graphitic components.

X-ray diffraction (XRD) measurements of the graphite and GO were performed using an Empyrean X-ray diffractometer (Panalytical Inc., Netherlands) using $\mathrm{CoK} \alpha_{1}(0.178901 \mathrm{~nm})$ radiation at: $40 \mathrm{kV}, 40 \mathrm{~mA}$, in the $2 \theta$ range of $5-40^{\circ}$.

Thermogravimetric analysis (TGA) was carried out using a TGA/DSC 2 instrument (Mettler Toledo, Switzerland) in nitrogen $\left(50 \mathrm{~mL} \mathrm{~min}{ }^{-1} \mathrm{~N}_{2}\right)$. Samples were heated from $25{ }^{\circ} \mathrm{C}$ up to $600{ }^{\circ} \mathrm{C}$ at $10^{\circ} \mathrm{C} \min ^{-1}$. 
Raman spectra were recorded at ambient temperature with a Renishaw inViaRaman spectrometer with an Ar-ion laser at an excitation wavelength of $514.5 \mathrm{~nm}$.

The oxygen barrier properties of samples were assessed using a Multiperm permeability analyzer (Extrasolution Srl, Capannori, Italy) equipped with an electrochemical sensor. Oxygen transmission rate $\left[O_{2} T R, \mathrm{~mL} \mathrm{~m}^{-2}(24 \mathrm{~h})^{-1}\right]$ data were determined according to the standard method of ASTM F2622-08, with a carrier flow $\left(\mathrm{N}_{2}\right)$ of $10 \mathrm{~mL} \mathrm{~min}^{-1}$ at $23{ }^{\circ} \mathrm{C}, 70 \%$ relative humidity $(\mathrm{RH})$, and $1 \mathrm{~atm}$ pressure difference on the two sides of the specimen. Each $\mathrm{O}_{2} T R$ value was derived from three replicates. Final oxygen permeability coefficients $\left(P^{\prime} O_{2}\right)$ were calculated according to the following equation [19]:

$$
P^{\prime} O_{2}=P O_{2} \times t=\frac{O_{2} T R}{\Delta p} \times t
$$

In eq $1, P^{\prime} O_{2}$ is the oxygen permeability coefficient, $P_{2}$ is the permeance (defined as the ratio of $\mathrm{O}_{2} T R$ to the difference between partial pressure of the gas on the two sides of film, $\Delta p$ ), and $t$ is the total thickness of the film. The SI unit of oxygen permeability is the $\mathrm{mol} \mathrm{m}^{-1} \mathrm{~s}^{-1} \mathrm{~Pa}^{-1}$. However, the most commonly used unit of $P^{\prime} O_{2}$ is $\left[\mathrm{mL} \mu \mathrm{m} \mathrm{m}^{-2}(24 \mathrm{~h})^{-1} \mathrm{~atm}^{-1}\right]$.

The tensile properties of pullulan and pullulan/GO films $(15 \mathrm{~mm}$ length $\times 3.2 \mathrm{~mm}$ width $)$ were tested on an Instron 5800R machine (Instron, UK) with a $500 \mathrm{~N}$ load cell and a crosshead speed of 2 $\mathrm{mm} \mathrm{min}^{-1}$ at room temperature and $\mathrm{RH}=50 \pm 2.0 \%$. Young's modulus (MPa), tensile strength (MPa), and elongation at break (\%) were determined in accordance with the ASTM 638-10 standard method. The final values are the mean of at least five replicates.

Total transmittance and haze were measured by Haze-Gard Dual-Transparency meter (BYKGardner GmbH, Germany) according to ASTM D 1003 standard method. Three replicates were performed for each type of film.

\subsection{Statistical analysis}

When necessary, the statistical significance of differences was determined by one-way analysis of variance (ANOVA) using JMP 5.0.1 software (SAS, Cary, NC, USA). Where appropriate, the mean 
values were compared using a least significant difference (LSD) test with a significance level of $(p)<$ 0.05 .

\section{Results and discussion}

\subsection{Characterisation and exfoliation of $G O$}

GO water dispersions were stable for several months (no precipitation occurred after 6 months) (inset in figure 1a). The morphology of the as-prepared GO sheets was characterised by AFM and TEM (figures. 1a-c).

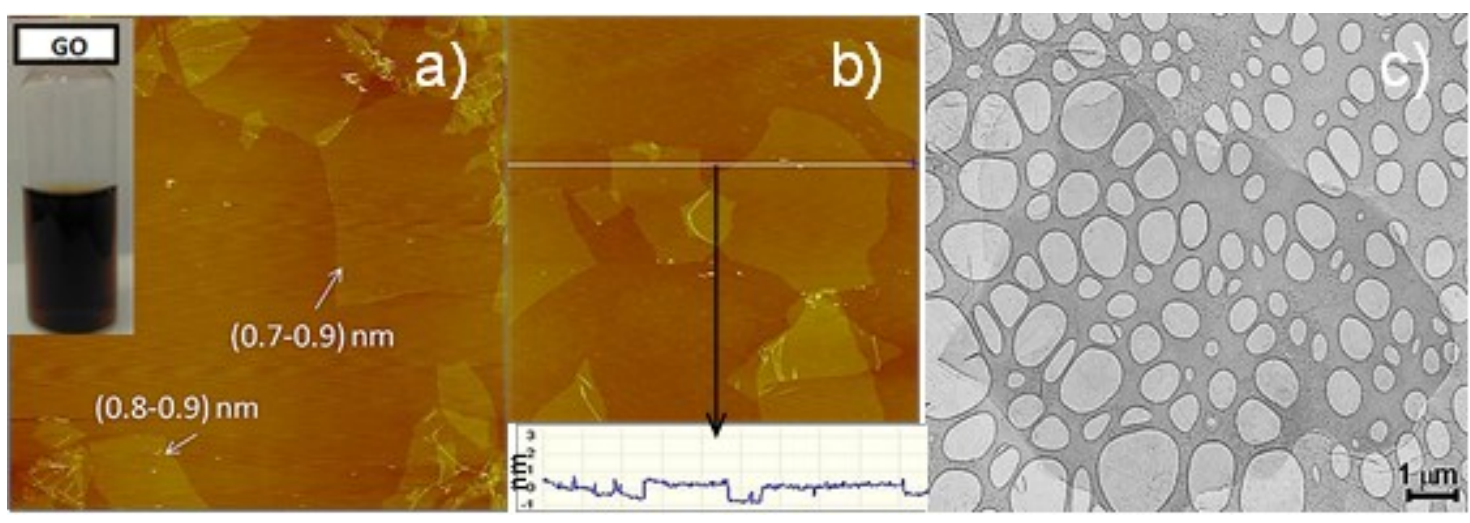

Figure 1. (a) $30 \times 30 \mu \mathrm{m}^{2}$ AFM height image of GO nanosheets (both individual and overlapping sheets are clearly visible) and GO water dispersion (0.15 wt\%) after 6 months storage at $23 \pm 2.5^{\circ} \mathrm{C}$ (inset); (b) $10 \times 10 \mu \mathrm{m}^{2}$ AFM height image with a cross section of GO sheets; (c) TEM image of exfoliated GO nanosheets on top of a holy carbon grid.

As shown in figure 1(a,b), the GO sheets' width ranged between 1.5 and $4.0 \mu \mathrm{m}$ (mean of $2.6 \mu \mathrm{m} \pm$ 0.8 ), whereas thickness values uniformly around $1.0 \mathrm{~nm}$ (mean of $0.95 \pm 0.18 \mathrm{~nm}$ ) suggested the complete exfoliation of GO sheets down to individual layers [20]. The mean aspect ratio calculated on the basis of several AFM observations was $1488 \pm 20$. The TEM image confirmed the full exfoliation of GO as individual sheets in water.

The oxidation degree of GO was characterised by using FTIR and XPS. The oxygen-containing functional groups were detected from the GO surface (figure 2a), and the results are consistent with the literature [21]. 

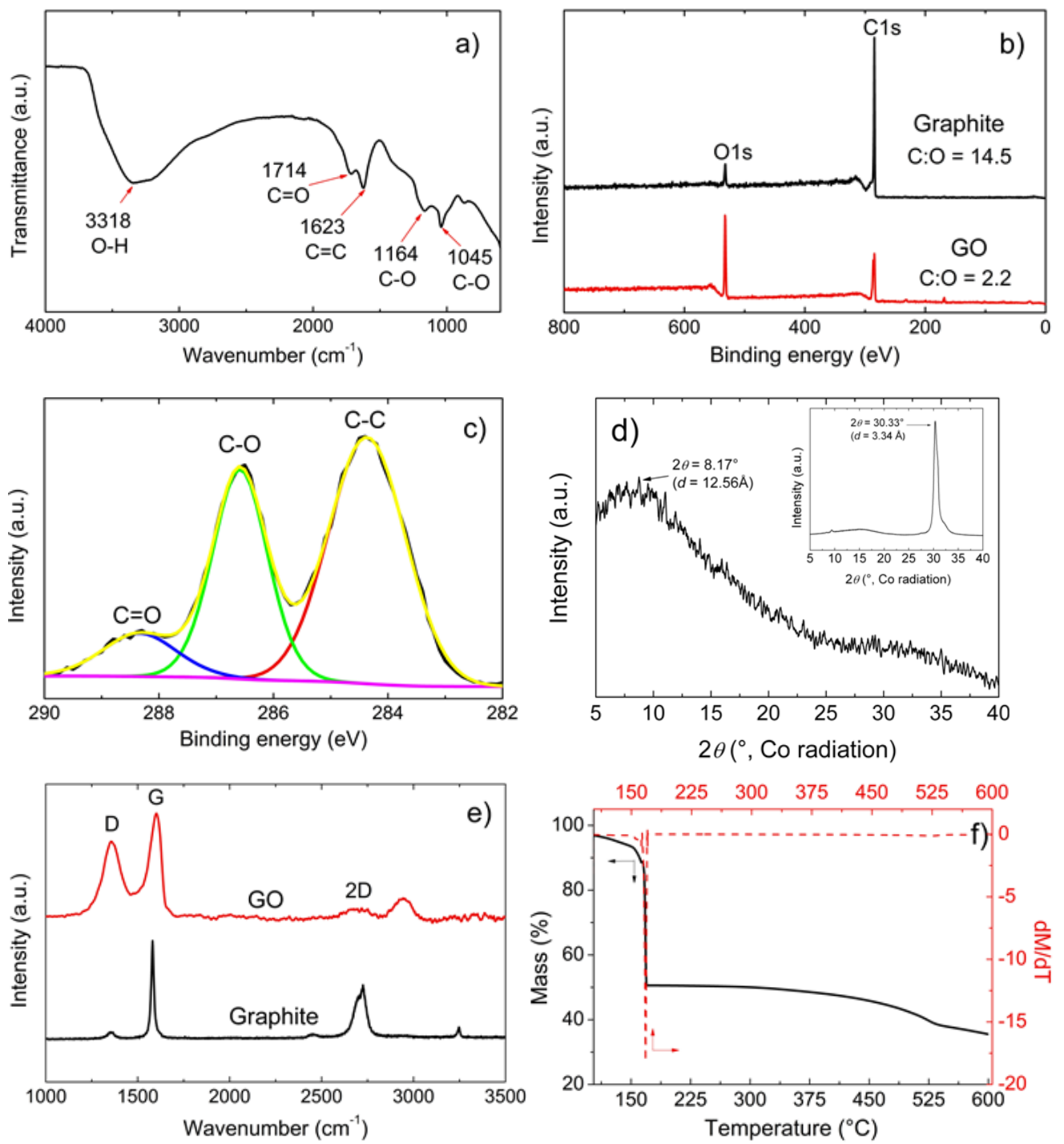

Figure 2. (a) FT-IR spectrum of GO powder; (b) XPS survey spectra of graphite and GO powders; (c) deconvolution of the $\mathrm{C}$ 1s peak of the XPS survey spectrum of GO; (d) XRD diffractogram of GO powder (the diffractogram of pristine graphite is reported for reference in the inset); (e) Raman spectra of graphite and GO; (f) TGA and DTG curves of GO.

The survey spectra of graphite and GO (figure $2 \mathrm{~b}$ ) yielded $\mathrm{C} / \mathrm{O}$ atomic ratios of 14.5 and 2.2, respectively, as a consequence of the oxidation process, which resulted in three main components corresponding to carbon atoms in different functional groups (figure 2c) [22]. The XRD pattern of GO is shown in figure $2 \mathrm{~d}$, whereas the reference pattern of pristine graphite is displayed in the inset of the same figure. The sharp (002) peak at $30.33^{\circ}$ (which corresponds to the peak at $2 \theta \sim 26.6^{\circ}$ when $\mathrm{CuK} \alpha$ radiation is used) [23] of pristine graphite completely disappeared in the GO samples, which suggests 
a decrease in crystallinity in GO samples. Only a very weak peak at $8.17^{\circ}$ (which corresponds to the peak at $2 \theta \sim 11.2^{\circ}$ when $\mathrm{CuK} \alpha$ radiation is used) [23] was observed in GO samples. The increased interlayer distance for GO (from $3.34 \AA$ for garphite to $12.56 \AA$ for GO), due to intense oxidation [24] was higher compared to other studies ( $d$-spacing $\sim 8 \AA$ ) [25-27] presumably due to interacting water molecules, which can give rise to a different spacing of the carbon layers from 6 to $12 \AA$ [28].

Raman spectra (figure 2e) of oxidised graphite showed a shifting of the $\mathrm{G}$ band to higher frequencies (from 1575 to $1603 \mathrm{~cm}^{-1}$ ) due to graphite amorphization [29], whereas the prominent D band of graphene at $1355 \mathrm{~cm}^{-1}$ clearly indicated the presence of structural defects induced by the attachment of hydroxyl and epoxide groups on the carbon basal plane [30]. In addition, the presence of a weak and broad 2D peak at $2719 \mathrm{~cm}^{-1}$ in the GO spectrum, which comes from an out-of-plane vibration mode after oxidation, is another indication of disorder [30]. The observation of G, D, and 2D bands agrees with previous characterisations of $\mathrm{GO}[23,31]$.

TGA results confirmed that GO was less stable than graphite from a thermal point of view (figure 2f), undergoing degradation at $\sim 170{ }^{\circ} \mathrm{C}$ with $50 \%$ mass loss due to the decomposition of labile oxygen functional groups [32].

\subsection{Oxygen barrier performance of pullulan/GO nanocomposite films}

The polar oxygen-containing functional groups on the surface of GO allowed its easy dispersion and exfoliation in pullulan water solutions. As shown in table 1, the solution-cast pullulan/GO films had thickness values ranging from 26 to $43 \mu \mathrm{m}$. Experimental $O_{2} T R$ values and the corresponding oxygen permeability $\left(\mathrm{P}^{\prime} \mathrm{O}_{2}\right)$ values as a function of the GO content are reported in table $1 . \mathrm{O}_{2}$ permeability of pristine pullulan film is sharply decreased with the addition of a low concentration of GO $(0.05 \mathrm{wt} \%$, $\phi>0.0005)$, which yielded $\sim 59 \%$ reduction in $P^{\prime} O_{2}\left[\right.$ from 6337 to $\left.2614 \mathrm{~mL} \mu \mathrm{m} \mathrm{m}^{-2}\left(24 \mathrm{~h}^{-1}\right) \mathrm{atm}^{-1}\right]$. For $\phi>0.0005$, a further increase in the barrier performance was obtained. The addition of $0.3 \mathrm{wt} \%$

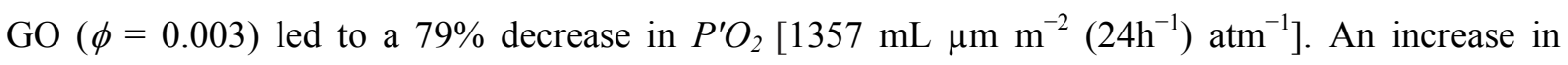
permeability was observed at $1.0 \mathrm{wt} \%(\phi=0.01)$ loading $\left[P^{\prime} O_{2}=1812 \mathrm{~mL} \mu \mathrm{m} \mathrm{m}^{-2}\left(24 \mathrm{~h}^{-1}\right) \mathrm{atm}^{-1}\right]$, which can be attributed to inhomogeneous distribution of GO sheets at higher concentration in the 
pullulan matrix. At low filler volume fraction $(\phi=0.002,0.2 \mathrm{wt} \%)$ there is no evidence of GO aggregates throughout the scanned cross-sectional area of the films-the morphology of pristine pullulan films (figure 3a) and films loaded with $0.2 \mathrm{wt} \% \mathrm{GO}$ (figure $3 \mathrm{~b}$ ) was very similar. This was likely due to the very low amount of GO used, which was below the detection limit of the instrument. As the filler concentration increased ( $\phi=0.01,1 \mathrm{wt} \%)$, stacking of GO sheets on top one of another was more often detected, indicating the tendency of exfoliated layers to re-aggregate into discrete entities (figure 3c).

Table 1. GO content, GO volume fraction $(\phi)$, thickness $(l)$, oxygen transmission rate $\left(O_{2} T R\right)$, and oxygen permeability coefficient $\left(\mathrm{P}^{\prime} \mathrm{O}_{2}\right)$ of bionanocomposite films at $70 \%$ relative humidity and 23

${ }^{\circ} \mathrm{C}$.

\begin{tabular}{|c|c|c|c|c|}
\hline $\begin{array}{l}\text { GO content } \\
\quad(\mathrm{wt} \%)\end{array}$ & $\phi^{\mathrm{a}}$ & $\begin{array}{c}l \\
(\mu \mathrm{m})\end{array}$ & $\begin{array}{c}O_{2} T R \\
{\left[\mathrm{~mL} \mathrm{~m}^{-2}\left(24 \mathrm{~h}^{-1}\right)\right]}\end{array}$ & 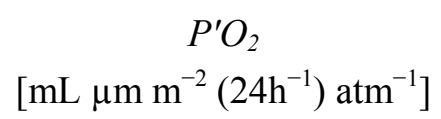 \\
\hline 0 & 0 & $35 \pm 2^{\mathrm{a}}$ & $181.04 \pm 20.05^{\mathrm{a}}$ & $6337^{\mathrm{a}}$ \\
\hline 0.05 & 0.00051 & $43 \pm 2^{b}$ & $60.79 \pm 5.97^{b}$ & $2614^{\mathrm{b}}$ \\
\hline 0.1 & 0.00102 & $26 \pm 2^{c}$ & $98.18 \pm 11.04^{\mathrm{c}}$ & $2553^{b}$ \\
\hline 0.2 & 0.00204 & $35 \pm 1^{\mathrm{a}}$ & $56.93 \pm 4.87^{\mathrm{b}}$ & $2277^{\mathrm{c}}$ \\
\hline 0.3 & 0.00305 & $41 \pm 2^{\text {bd }}$ & $33.09 \pm 2.94^{\mathrm{d}}$ & $1357^{\mathrm{d}}$ \\
\hline 1.0 & 0.01009 & $39 \pm 2^{d}$ & $46.47 \pm 3.98^{\mathrm{bd}}$ & $1812^{\mathrm{cd}}$ \\
\hline
\end{tabular}

${ }^{a}$ Calculated for a given GO density $(\rho)=1.8 \mathrm{~g} \cdot \mathrm{cm}^{-3}[10]$ and pullulan density $(\rho)=1 \mathrm{~g} \cdot \mathrm{cm}^{-3}$.

Different superscripts within a group (i.e., within each parameter) denote a statistically significant difference ( $p$ $<0.05$ ). Error around the mean value represents the standard deviation. 
Common commercial packaging materials exhibit higher $\mathrm{P}^{\prime} \mathrm{O}_{2}$ values as compared to the pullulan/GO films obtained in our work with less than $0.3 \mathrm{wt} \%$ of GO (table 2). For example, the $\mathrm{P}^{\prime} \mathrm{O}_{2}$ value of PET film at $70 \% \mathrm{RH}$ and $23{ }^{\circ} \mathrm{C}$ is $1560 \mathrm{~mL} \mu \mathrm{m} \mathrm{m}^{-2}\left(24 \mathrm{~h}^{-1}\right)$ atm ${ }^{-1}$ [33] $P^{\prime} O_{2}$ values of OPP and LDPE

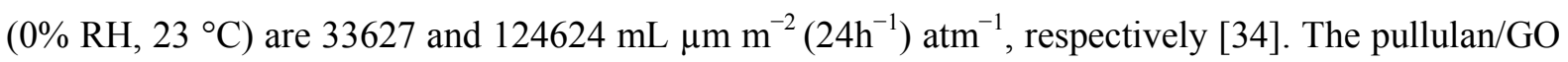
films with exceptional oxygen barrier properties at $0.3 \mathrm{wt} \%$ of GO are also superior than most polymer nanocomposites with potential application in the packaging industry when considering both filler loading and environmental relative humidity. As far as the clay nanoplatelets are concerned, clay loadings of 5-10 $\mathrm{wt} \%$ are required in order to improve the gas barrier performance of polymers (table 2) [36, 38-41]. For GO polymer/biopolymer systems the excellent barrier performance found e.g. for the $\mathrm{PVOH} / \mathrm{GO}$ composites has to be considered in light of the experimental $\mathrm{RH}$ values $(0 \%$ or $50 \%$ $\mathrm{RH})$. 
Table 2. Permeability coefficient of most common plastic films used in food packaging and of typical polymer/biopolymer nanocomposites based on montmorillonite (MMT) and GO at different loadings and environmental relative humidity $(\mathrm{RH})$.

\begin{tabular}{|c|c|c|c|c|}
\hline Film type & Filler content & $\begin{array}{l}\mathrm{RH} \\
(\%)\end{array}$ & $\begin{array}{c}P^{\prime} O_{2} \\
\left(\mathrm{~mL} \mu \mathrm{m} \mathrm{m}^{-2} 24 \mathrm{~h}^{-1} \mathrm{~atm}^{-1}\right)\end{array}$ & Ref. \\
\hline PET & - & 70 & 1560 & {$[33]$} \\
\hline OPP & - & 0 & 33627 & {$[34]$} \\
\hline LDPE & - & 0 & 124624 & {$[34]$} \\
\hline PP & - & 80 & 43307 & {$[35]$} \\
\hline PVOH & - & 80 & 2756 & {$[35]$} \\
\hline Nylon, 6, 6 & - & 80 & 5906 & {$[35]$} \\
\hline $\mathrm{EVOH}$ & - & 80 & 2756 & {$[35]$} \\
\hline HDPE & - & 0 & 41040 & {$[36]$} \\
\hline PLA/GO & 1.37 vol. $\%$ & 50 & 18032 & {$[10]$} \\
\hline $\mathrm{PVOH} / \mathrm{GO}$ & 0.07 vol $\%$ & 0 & $<0.0432$ & {$[37]$} \\
\hline $\mathrm{PVOH} / \mathrm{GO}$ & 0.72 vol $\%$ & 50 & 240 & [9] \\
\hline Cellulose/GO & $1.64 \mathrm{vol} \%$ & 50 & 100 & {$[38]$} \\
\hline HDPE/MMT & 4 vol\% & 0 & 23560 & {$[36]$} \\
\hline $\mathrm{PP} / \mathrm{MMT}$ & $10 \mathrm{wt} \%$ & 0 & 47600 & [39] \\
\hline Chitosan/MMT & $5 \mathrm{wt} \%$ & 50 & 36300 & {$[40]$} \\
\hline Gelatin/MMT & $9 \mathrm{wt} \%$ & 50 & 114.4 & {$[41]$} \\
\hline Pullulan/GO & $0.31 \mathrm{vol} \%$ & 70 & 1357 & This study \\
\hline
\end{tabular}

It is well known that the $\mathrm{O}_{2}$ barrier performance in -OH-rich polymers starts to decrease exponentially at RHs $\sim 65-75 \%$, depending on chemical factors such as copolymerization ratio of ethylene and vinyl alcohol in EVOH [42].

Figure 4 displays the experimental $P^{\prime} \mathrm{O}_{2}$ data of the bionanocomposite films at $70 \% \mathrm{RH}$ and 23 ${ }^{\circ} \mathrm{C}$, together with theoretical predictions based on Nielsen's (eq. 2) and Cussler's (eqs. 3a and 3b) permeation theoretical models, which describe the permeation phenomenon for impermeable square platelets dispersed in a continuous matrix [43-45]: 


$$
\begin{aligned}
& P_{0} / P \cdot(1-\phi)=1+(\alpha \phi) / 2 \\
& P_{0} / P \cdot(1-\phi)=1+(\alpha \phi)^{2} / 4 \\
& P_{0} / P \cdot(1-\phi)=(1+\alpha \phi / 3)^{2}
\end{aligned}
$$

where $P_{0}$ is the permeability parameter of the pure biopolymer coating, $P$ is the permeability parameter of the bionanocomposite coatings, $\alpha$ is the aspect ratio of the platelets (the width divided by the thickness), and $\phi$ is the volume fraction of the platelets dispersed in the biopolymer matrix.

$P^{\prime} \mathrm{O}_{2}$ experimental data are well fitted with Nielsen's prediction for $\alpha=500$ (figure 4a). However, a clear deviation was observed for the highest $\phi$ value, which can be reasonably due to the aggregation of GO at high loading. In turn, this would reduce the effective aspect ratio of GO sheets. It should be noted that the prediction by Nielsen's model applies for a regular array distribution (also called "bricks-and-mortar", i.e. regularly spaced flake "bricks" held together by polymer "mortar") of non-overlapping, fully intercalated platelets perpendicular to the gas diffusion direction $[44,46]$. In practice, Nielsen's model is accurate in the dilute regime $(\alpha \phi<<1)$, which is in practice verified for low concentrations $(\phi<<1)$ of exfoliated nanoplatlets [47]. Since, in our study, $\alpha \sim 1500$ and $0.0005<$ $\phi<0.01$, the product $\alpha \phi$ varies from $0.8-15.1$, which locates our system between dilute and semidilute regimes, the latter being verified when the flake concentration is small but the flakes overlap. This means that $\phi<<1, \alpha>>1$, and $\alpha \phi>>1$ [48].

Due to the inadequacy of Nielsen's model in the semi-dilute regime, we also took into consideration Cussler's models for regular and random arrays of ribbons in a semi-dilute regime, where permeability varies linearly with the square of the factor $\alpha \phi\left[\right.$ i.e., $\left.(\alpha \phi)^{2}\right]$, which is contrary to Nielsen's model [44].The most relevant observation is that Cussler's models approached the best fitting of experimental data for $1000<\alpha<2000$, which is in line with our experimental values gained by AFM. On one hand, this suggests an underestimation of the GO aspect ratio provided by Nielsen's model compared to Cussler's models. 

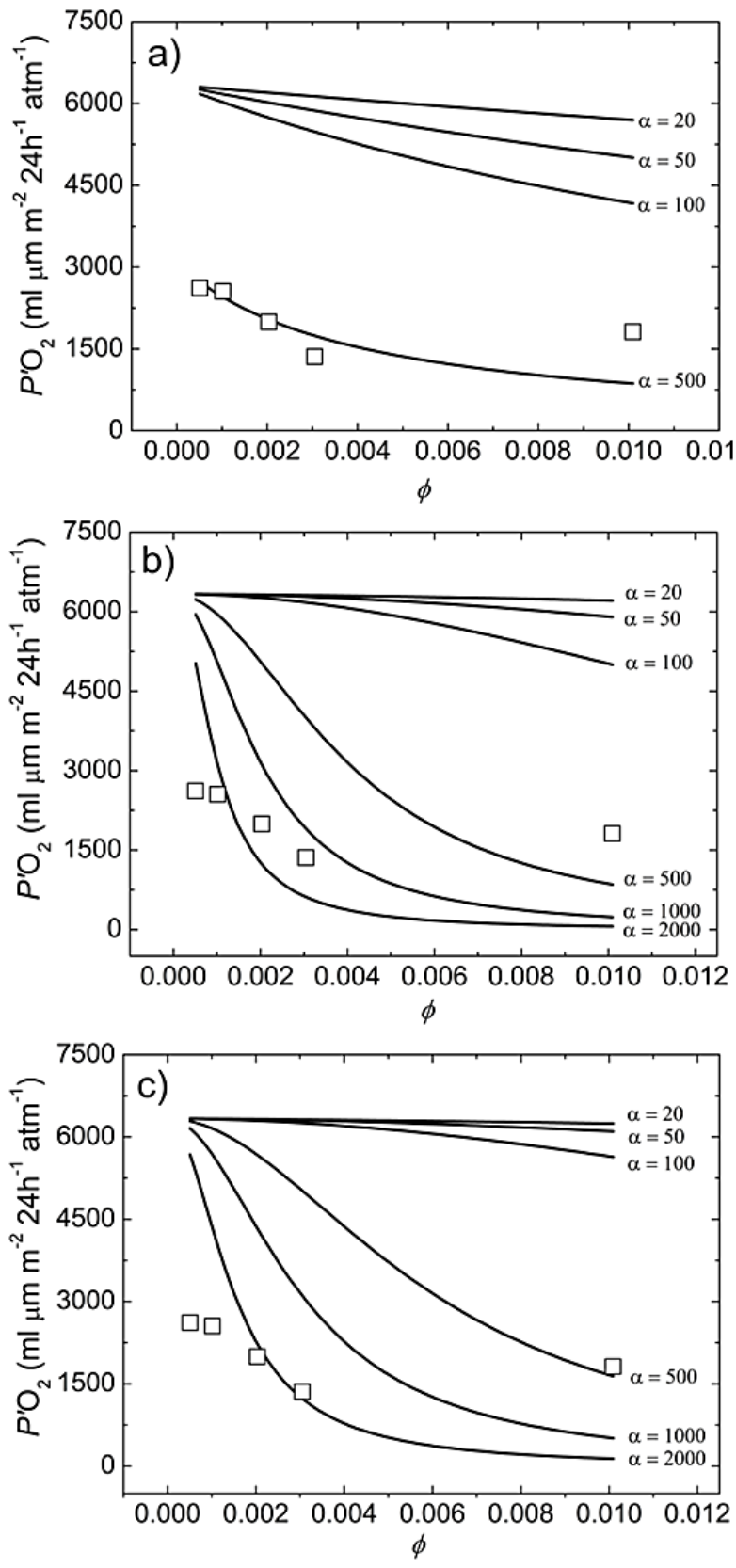

Figure 4. Oxygen permeability of bionanocomposite films. Experimental values ( $\square$ ), and values predicted by Nielsen's model (panel a, eq. 2 in the text) and Cussler's models (panels b and c, eqs. 3a and $3 b$ in the text), for different aspect ratios $(\alpha)$ are depicted.

On the other hand, the model prediction strongly supports the higher aspect ratio of 2D GO compared to the widely used inorganic clays, e.g. montmorillonite, which have been reported to have aspect ratios $(\alpha)$ between 10 and 100 for a similar pullulan-based system [33, 49]. It is well known that this parameter is of great importance for the design of high performance barrier materials (e.g., 
films and coatings), because the performance provided by GO is in principle much more effective than clays due to the longer pathway offered to the permeant (e.g., oxygen molecules).

\subsection{Physical properties of pullulan/GO nanocomposites}

Tensile strength, Young's modulus, and elongation at break values are reported in table 3 for the different formulations. Unmodified pullulan films had tensile strength of $\sim 50 \mathrm{MPa}$, Young's modulus of $\sim 1556 \mathrm{MPa}$, and an elongation at break of $\sim 4.36 \%$, which is in line with the values found in literature [50]. The addition of GO up to $0.2 \mathrm{wt} \%$ led to a significant improvement in tensile strength, Young's modulus, and elongation at break, with increases of around $40 \%, 44 \%$, and $52 \%$, respectively, compared to the pristine pullulan films. More modest increases in strength (19\%) and modulus (33\%), and a reduction in the strain to failure (3\%), were found at $0.3 \mathrm{wt} \%$. Ultimately, the tensile strength and Young's modulus increased by around $49 \%$ and $104 \%$, while the elongation at break decreased by around $4 \%$ at $1.0 \mathrm{wt} \%$ of GO $(p<0.05)$. Thus, it is suggested that the GO loading of approximately $0.3 \mathrm{wt} \%$ acts as a transition from a ductile to a more brittle behavior of the nanocomposite. Moreover, the variation of the modulus with the GO content becomes nonlinear at 0.3 wt $\%$, which we propose is associated with the decreasing level of exfoliation of GO with its increasing content.

To verify this hypothesis, the modulus was predicted using a modified Mori-Tanaka model, which accounts for the degree of exfolation, in terms of the number of GO monolayers in each stack (tactoid) [51]. The value of GO Young's modulus was assumed as 207.60GPa [52], while the length $(l)$ and thickness $(d)$ of an individual GO sheet were determined from AFM analysis as $2.6 \mu \mathrm{m}$ and $0.95 \mathrm{~nm}$, respectively. Moreover, the Poisson's ratio $(v)$ for the polymer matrix and GO used in this paper were 0.35 and 0.20 , respectively. For intercalated morphologies (i.e., 2 and 3 platelets in the tactoid), the modulus of the gallery was assumed to be equal to that of the pullulan. As there was no precise experimental evidence on the GO orientation within the nanocomposite samples, two extreme cases were investigated with the model, i.e. fully aligned and randomly oriented. For completeness, the predictions were also compared with the Halpin-Tsai model assuming fully exfoliated systems. 
Table 3. Physical properties of pullulan/GO nanocomposite films with different GO concentrations.

\begin{tabular}{|c|c|c|c|c|c|}
\hline \multirow[b]{2}{*}{$\begin{array}{l}\text { GO content } \\
(\mathrm{wt} \%)\end{array}$} & \multicolumn{3}{|c|}{ Mechanical properties } & \multicolumn{2}{|c|}{ Optical properties } \\
\hline & $\begin{array}{c}\text { Tensile strength } \\
(\mathrm{MPa})\end{array}$ & $\begin{array}{l}\text { Young's } \\
\text { modulus } \\
\text { (MPa) }\end{array}$ & $\begin{array}{c}\text { Elongation } \\
(\%)\end{array}$ & $\begin{array}{c}\text { Transmittance } \\
(\%)\end{array}$ & $\begin{array}{c}\text { Haze } \\
(\%)\end{array}$ \\
\hline 0 & $50.05 \pm 4.01^{\mathrm{a}}$ & $1556 \pm 92^{a}$ & $4.36 \pm 0.76^{\mathrm{a}}$ & $93.1 \pm 0.6^{\mathrm{a}}$ & $0.40 \pm 0.01^{\mathrm{a}}$ \\
\hline 0.05 & $57.49 \pm 4.55^{\mathrm{abc}}$ & $1819 \pm 164^{\mathrm{a}}$ & $5.65 \pm 1.54^{\mathrm{ab}}$ & $93.4 \pm 0.3^{\mathrm{a}}$ & $0.39 \pm 0.03^{\mathrm{a}}$ \\
\hline 0.1 & $54.65 \pm 16.89^{\mathrm{ab}}$ & $1940 \pm 605^{\mathrm{a}}$ & $5.85 \pm 2.77^{\mathrm{ab}}$ & $93.4 \pm 0.3^{\mathrm{a}}$ & $0.38 \pm 0.03^{\mathrm{a}}$ \\
\hline 0.2 & $70.10 \pm 7.77^{\mathrm{bc}}$ & $2246 \pm 811^{\mathrm{ab}}$ & $6.61 \pm 0.62^{b}$ & $92.3 \pm 0.1^{\mathrm{a}}$ & $0.39 \pm 0.02^{\mathrm{a}}$ \\
\hline 0.3 & $64.03 \pm 8.91^{\mathrm{abc}}$ & $2432 \pm 54^{\mathrm{b}}$ & $4.64 \pm 0.59^{\mathrm{ab}}$ & $92.5 \pm 0.7^{\mathrm{a}}$ & $0.37 \pm 0.08^{\mathrm{a}}$ \\
\hline 0.5 & $69.57 \pm 18.92^{\mathrm{bc}}$ & $2647 \pm 717^{\mathrm{bc}}$ & $4.72 \pm 1.01^{\mathrm{ab}}$ & $91.9 \pm 0.1^{\mathrm{a}}$ & $0.36 \pm 0.05^{\mathrm{a}}$ \\
\hline 1.0 & $74.30 \pm 13.89^{c}$ & $3178 \pm 538^{\mathrm{c}}$ & $4.18 \pm 1.14^{\mathrm{a}}$ & $90.1 \pm 0.9^{b}$ & $0.47 \pm 0.09^{\mathrm{a}}$ \\
\hline
\end{tabular}

Different superscripts within a group (i.e., within each parameter) denote a statistically significant difference ( $p$ $<0.05$ ). Error around the mean value represents the standard deviation.

The modulus for exfoliated and randomly oriented GO is given by [53]

$$
E_{r}=E_{m}\left[\frac{3}{8} \frac{1+\eta_{L} \xi \phi}{1-\eta_{L}}+\frac{5}{8} \frac{1+2 \eta_{T} \phi}{1-\eta_{T} \phi}\right],
$$

where $\eta_{L}=E_{m} \frac{E_{g} / E_{m}-1}{E_{g} / E_{m}+\xi}, \quad \eta_{T}=E_{m} \frac{E_{g} / E_{m}-1}{E_{g} / E_{m}+2}$, and $\xi=\frac{2 l}{3 d}, E_{r}$ represents the Young's modulus of the composites with randomly distributed GO sheets. $E_{g}$ and $E_{m}$ are Young's moduli of GO and pullulan, respectively. $l$ and $d$ refer to the average length and thickness of an individual GO sheet, whereas $\phi$ is the volume fraction of GO in the nanocomposites (see table 1).

The modulus predictions from the models suggest that the GO nanoparticles have a preferred orientation (tending to a fully aligned one) with a domination of well exfoliated GO, up to around of $0.3 \mathrm{wt} \%$, as shown in figure 5 . It is proposed that the morphology becomes dominated by intercalated tactoids, as suggested by a nonlinear trend in the modulus and the predictions by the Mori-Tanaka model with fully aligned tactoids composed of two platelets at $1 \mathrm{wt} \% \mathrm{GO}-$ this is also in qualitative agreement with conclusions on the barrier properties (see previous section), where the permeability was found to increase at $1 \mathrm{wt} \% \mathrm{GO}$ due to the presence of tactoids. 


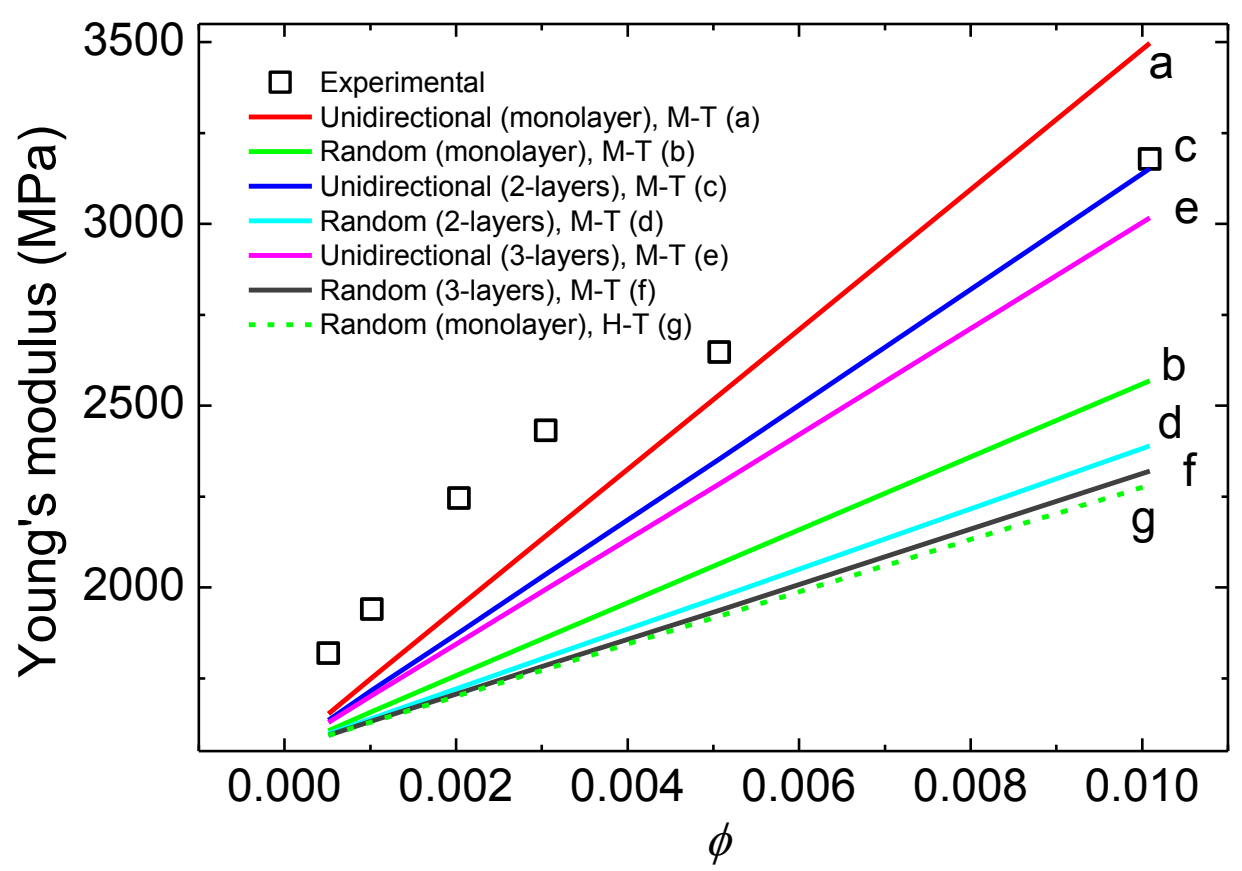

Figure 5. Experimental Young's modulus values of bionanocomposite films and theoretical simulation for distribution of GO sheets in the pullulan matrix according to Mori-Tanaka (eq. 10-12, ref. 51) and Halpin-Tsai (eq. 4 in the text) theoretical models.

It must be mentioned that the assumption of random orientation resulted in a significant underprediction of experimental results, suggesting a preferred orientation of GO nanoparticles. For the given weight fractions, both the Mori-Tanaka and Halpin-Tsai models provided nearly identical predictions for the fully exfoliated and fully aligned case. However, the Mori-Tanaka model predicted higher values for the randomly oriented and fully exfoliated case, as compared to the Halpin-Tsai model-this is because the orientation-averaged Mori-Tanaka model is an upper-bound in this case [51].

Despite reasonably good predictions, as shown above, higher accuracy can be yet achieved by taking into consideration pullulan-GO interactions within the two models. These interactions, mainly resulting from the presence presence of epoxy and hydroxyl groups on the GO planar surfaces, and to smaller extent from the carboxyl groups on the edges [54] (see Figure 2), are believed to contribute to significant non-covalent forces (e.g., hydrogen bonding) at the pullulan/GO interface. These forces are believed to affect the interfacial adhesion, and more importantly the polymer chain mobility near 
the pullulan/GO interface. The stress transfer behaviour in the nanocomposites [25], and the properties of the polymer matrix in the vicinity of GO platelets will be thus modified, leading to a possible formation of a polymer interphase. The applied models did not account for the presence of the interphase effects, and the work on improved models is ongoing.

Optical properties of materials are particularly important in certain sectors, where they can impact either the performance of the final material or the consumer's choice. In the food packaging field, both aspects are relevant and worth considering when designing a new material [1]. As confirmed by the transmittance and haze values reported in table 3 , all the pullulan/GO bionanocomposite films were fully comparable with pristine pullulan samples, with the exception of the transmittance value for the nanocomposite film at the highest GO concentration (1.0 wt $\%)$. Haze values, in particular, were below the $3 \%$ threshold, which is generally deemed adequate in food packaging for a proper display of the products [33], although some plastics exhibit haze values slightly higher (e.g., low-density polyethylene) [55]. Overall, the final films had a smooth, uniform, and transparent appearance, although the colour of composite films gradually shifted from colourless to yellow-brown as the GO content increased, as displayed in figure 6. Based on these results, the pullulan/GO nanocomposite films, especially at the lowest GO concentrations, exhibited acceptable optical properties for exploring new packaging applications.

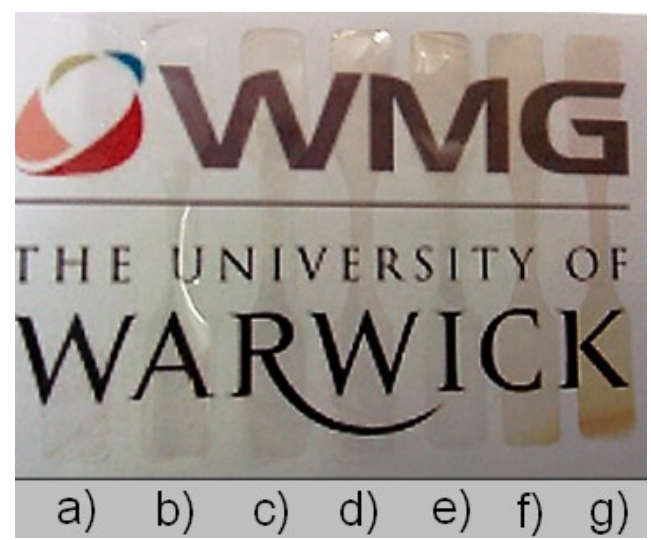

Figure 6. Digital camera images of dog-bone shaped specimens of a) pristine pullulan and pullulan/GO films with different GO concentrations: b) $0.05 \mathrm{wt} \%$, c) $0.1 \mathrm{wt} \%$, d) $0.2 \mathrm{wt} \%$, e) 0.3 wt $\%$, f) $0.5 \mathrm{wt} \%$, and g) $1.0 \mathrm{wt} \%$. 


\section{Conclusions}

High performance pullulan/GO nanocomposite films have been successfully prepared. The chemical affinity between GO and pullulan significantly benefits the interfacial adhesion between the two phases. The disperison and exfoliation of GO nanosheets in pullulan contributed to the enhanced oxygen barrier ( $81.7 \%$ increase) and mechanical properties (104\% elastic modulus increase) of the final nanocomposites. SEM observation and the modelling results of the experimental oxygen permeability and tensile modulus values suggested that GO sheets are randomly arranged and aligned parallel to the surface of the biopolymer matrix. The findings of this work reflect the fact that the higher oxygen barrier and mechanical properties of pullulan/GO nanocomposites represent a promising alternative to the currently synthetic polymer films. Nonetheless, the optical clarity of the nanocomposites was kept adequate for most packaging applications. It is thus expected that pullulan/GO nanocomposite films and coatings with good oxygen barrier, mechanical properties, and optical clarity will find wide applications in the food packaging sector. 


\section{References}

[1] Uysal Unalan I, Cerri G, Marcuzzo E, Cozzolino C A and Farris S 2014 Nanocomposite films and coatings using inorganic nanobuilding blocks (NBB): current applications and future opportunities in the food packaging sector RSC Adv. 4 29393-428

[2] Zhu Y, Murali S, Cai W, Li X, Suk J W, Potts J R and Ruoff R S 2010 Graphene and graphene oxide: synthesis, properties, and applications Adv. Mater. 22 3906-24

[3] Edwards R S and Coleman K S 2013 Graphene synthesis: relationship to applications Nanoscale 5 38-51

[4] Han D, Yan L, Chen W, Li W and Bangal P R 2011 Cellulose/graphite oxide composite films with improved mechanical properties over a wide range of temperature Carbohydr. Polym. $\mathbf{8 3}$ $966-72$

[5] Gao J, Chen F, Wang K, Deng H, Zhang Q, Bai H and Fu Q 2011 A promising alternative to conventional polyethylene with poly(propylene carbonate) reinforced by graphene oxide nanosheets J. Mater. Chem. 21, 17627-30

[6] JChen T, Fu Y. J, An Q F, Lo S C, Huang S H, Hung W S, Hu C C, Lee K R and Lai J Y 2013 Tuning nanostructure of graphene oxide/polyelectrolyte LbL assemblies by controlling pH of GO suspension to fabricate transparent and super gas barrier films Nanoscale 5 908188

[7] Wan C and Chen B 2012 Reinforcement and interphase of polymer/graphene oxide nanocomposites J. Mater. Chem. 22 3637-46

[8] Huang $\mathrm{Y}$, Wang $\mathrm{T}$, Zhao $\mathrm{X}$, Wang $\mathrm{X}$, Zhou L, Yang, Liao $\mathrm{F}$ and Ju Y Poly(lactic acid)/graphene oxide-ZnO nanocomposite films with good mechanical, dynamic mechanical, anti-uv and antibacterial properties $2014 \mathrm{~J}$. Chem. Technol. Biotechnol. DOI: $10.1002 /$ jctb. 4476

[9] Huang H D, Ren P G, Chen J, Zhang W Q, Ji X and Li Z M 2012 High barrier graphene oxide nanosheet/poly (vinyl alcohol) nanocomposite films J. Membr. Sci. 409 156-63 
[10] Huang H D, Ren P G, Xu J Z, Xu L, Zhong G J, Hsiao B S and Li Z M 2014 Improved barrier properties of poly(lactic acid) with randomly dispersed graphene oxide nanosheets J. Membr. Sci. $464110-8$

[11] Yoo J T, Lee S B, Lee C K, Hwang S W, Kim C R, Fujigaya T, Nakashima N and Shim J K Graphene oxide and laponite composite films with high oxygen-barrier properties Nanoscale 6 10824-30

[12] Ghosh T K et al 2014 Assessment of morphology and property of graphene oxidehydroxypropylmethylcellulose nanocomposite films Int. J. Biol. Macromol. 66 338-45

[13] Farris S, Unalan I U, Introzzi L, Fuentes-Alventosa J M and Cozzolino C A 2014 Pullulan-based films and coatings for food packaging: present applications, emerging opportunities, and future challenges J. Appli. Polym. Sci. 131 40539-51

[14] Han D, Yan L, Chen W and Li W. 2011 Preparation of chitosan/graphene oxide composite film with enhanced mechanical strength in the wet state Carbohydr. Polym. 83 653-8

[15] Leathers T D 2002 Polysaccharides II: Polysaccharides from Eukaryotes vol 6, ed E J Vandamme, S De Baets and A Steinblichel (Germany:Wiley-VCH) pp 1-35

[16] Singh R S, Saini G K and Kennedy J F 2008 Microbial sources, production and applications Carbohydr. Polym. 73 515-31

[17] Leathers T D 2003 Biotechnological production and applications of pullulan Appl. Microbiol. Biotechnol. 62 468-73

[18] Farris S, Introzzi L, Fuentes-Alventosa J M, Santo N, Rocca R and Piergiovanni L 2012 Selfassembled pullulan-silica oxygen barrier hybrid coatings for food packaging applications $J$. Agric. Food Chem. $60782-90$

[19] Svagan A J, Åkesson A, Cárdenas M, Bulut S, Knudsen J C, Risbo J and Plackett D 2012 Transparent films based on PLA and montmorillonite with tunable oxygen barrier properties Biomacromolecules 13 397-405 
[20] Schniepp H C, Li J L, McAllister M J, Sai H, Herrera-Alonso M, Adamson D H, Prud'homme R K, Car R, Saville D A and Aksay I A 2006 Functionalized single graphene sheets derived from splitting graphite oxide J. Phys. Chem. B $1108535-9$

[21] Wang B, Lou W, Wan X and Hao J 2012 Relationship between dispersion state and reinforcement effect of graphene oxide in microcrystalline cellulose-graphene oxide composite filmsJ. Mater. Chem. 22 12859-66

[22] Stankovich S, Dikin D A, Piner R D, Kohlhaas K A, Kleinhammes A, Jia Y, Wu Y, Nguyen S T and Ruoff R S 2007 Synthesis of graphene-based nanosheets via chemical reduction of exfoliated graphite oxide Carbon, 45 1558-65

[23] Bai X, Wan C, Zhang Y and Zhai Y 2011 Reinforcement of hydrogenated carboxylated nitrile-butadiene rubber with exfoliated graphene oxide Carbon 49 1608-13

[24] Cui P, Lee J, Hwang E and Lee H 2011 One-pot reduction of graphene oxide at subzero temperatures Chem. Commun. 47, 12370-72

[25] Yang X, Tu Y, Li L, Shang S and Tao X M 2010 Well-dispersed chitosan/graphene oxide nanocomposites ACS Appl. Mater. Interfaces 2 1707-13

[26] Justin R and Chen B 2014 Characterisation and drug release performance of biodegradable chitosan-graphene oxide nanocomposites Carbohydr. Polym. 103 70-80

[27] Ionita M, Pandele M A and Iovu H 2013 Sodium alginate/graphene oxide composite films with enhanced thermal and mechanical properties Carbohydr. Polym. 94 339-44

[28] Buchsteiner A, Lerf A and Pieper $2006 \mathrm{~J}$ Water dynamics in graphite oxide investigated with neutron scattering J. Phys. Chem. B $11022328-38$

[29] Kudin K N, Ozbas B, Schniepp H C, Prud'Homme R K, Aksay I A and Car R R 2008 Raman spectra of graphite oxide and functionalized graphene sheets Nano Lett. 8 36-41

[30] Eda G, Fanchini G and Chhowalla M 2008 Ultrathin films of reduced graphene oxide as a transparent and flexible electronic material Nat. Nanotechnol. $3270-4$

[31] Yadav M, Rhee K Y and Park S J 2014 Synthesis and characterization of graphene oxide/carboxymethylcellulose/alginate composite blend films Carbohydr. Polym. 110 18-25 
[32] Chen W, Yan L and Bangal P R 2010 Preparation of graphene by the rapid and mild thermal reduction of graphene oxide induced by microwaves Carbon 48 1146-52

[33] Introzzi L, Blomfeldt T O, Trabattoni S, Tavazzi S, Santo N, A. Schiraldi A, Piergiovanni L and Farris S 2012 Ultrasound-assisted pullulan/montmorillonite bionanocomposite coating with high oxygen barrier properties Langmuir 28 11206-14

[34] Farris S, Introzzi L and Piergiovanni L 2009 Evaluation of bio-coating as a solution to improve barrier, friction and optical poperties of plastic films Packag. Technol. Sci. 200922 $69-83$

[35] Mount E 2009 The Wiley Encyclopedia of Packaging Technology $3^{\text {rd }}$ edition, ed K L Yam (Hoboken: Wiley) pp 477-86.

[36] Osman M A, Rupp J E P and Suter U W 2005 Gas permeation properties of polyethylenelayered silicate nanocomposites J. Mater. Chem. 15 1298-1304

[37] Chen J T, Fu Y J, An Q F, Lo S C, Zhong Y Z, Hu C C, Lee K R and Lai J Y 2014 Enhancing polymer/graphene oxide gas barrier film properties by introducing new crystals Carbon $\mathbf{7 5}$ $443-51$

[38] Huang H D, Liu C Y, Li D, Chen Y H, Zhong G J and Li Z M Ultra-low gas permeability and efficient reinforcement of cellulose nanocomposite films by well-aligned graphene oxide nanosheets J. Mater. Chem. A 2 15853-63

[39] Choi R N, Cheigh C I, Lee S Y and Chung M S 2011 Preparation and properties of polypropylene/clay nanocomposites for food packaging J. Food Sci. 76 N62-7

[40] Hong S I, Lee J H, Bae H J, Koo S Y, Lee H S, Choi J H, Kim D H, Park S -H and Park H J 2011 Effect of shear rate on structural, mechanical, and barrier properties of chitosan/montmorillonite nanocomposite film J. Appl. Polym. Sci. $1192742-9$ 
[41] Bae H J, Park H J, Hong S I, Byun Y J, Darby D O, Kimmel R M and Whiteside W S 2009 Effect of clay content, homogenization $\mathrm{RPM}, \mathrm{pH}$, and ultrasonication on mechanical and barrier properties of fish gelatin/montmorillonite nanocomposite films LWT - Food Sci. Technol. 42 1179-86

[42] Zhang Z, Britt I J and Tung M A 2011 Permeation of oxygen and water vapor through EVOH films as influenced by relative humidity J. Appl. Polym. Sci. 82 1866-72

[43] Nielsen L E 1967 Models for the permeability of filled polymer systems J. Macromol. Sci. Chem. 1 929-42

[44] Lape N K, Nuxoll E E and Cussler E L 2004 Polydisperse flakes in barrier films J. Membr. Sci. $23629-37$

[45] Takahashi S, Goldberg H A, Feeney C A, Karim D P, Farrell M, O'Leary K and Paul D R 2006 Gas barrier properties of butyl rubber/vermiculite nanocomposite coatings Polymer 47 3083-93

[46] Choudalakis G and Gotsis A 2009 Permeability of polymer/clay nanocomposites: a review Eur. Polym. J. 45 967-84

[47] Picard E, Vermogen A, Gérard J F and Espuche E 2007 Barrier properties of nylon 6montmorillonite nanocomposite membranes prepared by melt blending: influence of the clay content and dispersion state: consequences on modelling J. Membr. Sci. 292 133-44

[48] DeRocher J P, Gettelfinger B T, Wang J, Nuxoll E E and Cussler E 2005 Barrier membranes with different sizes of aligned flakes J. Membr. Sci. 254 21-30

[49] Fuentes-Alventosa J M, Introzzi L, Santo N, Cerri G, Brundu A and Farris S 2013 Selfassembled nanostructured biohybrid coatings by an integrated 'sol-gel/intercalation approach RSC Adv. 3 25086-96

[50] Fernandes S C M, Sadocco P, Causio J, Silvestre A J D, Mondragon I and Freire C S R 2014 Antimicrobial pullulan derivative prepared by grafting with 3-aminopropyltrimethoxysilane: characterization and ability to form transparent films Food Hydrocolloid $\mathbf{3 5} 247-52$ 
[51] Figiel L and Buckley C P 2009 Elastic constants for an intercalated layered-silicate/polymer nanocomposite using the effective particle concept- a parametric study using numerical and analytical continuum approaches Comp. Mater. Sci. 44 1332-43

[52] Suk J W, Piner R D, An J and Ruoff R S 2010 Mechanical properties of monolayer graphene oxide ACS Nano 4 6557-64

[53] Zhao X, Zhang Q, Chen D and Lu P 2010 Enhanced mechanical properties of graphene-based poly (vinyl alcohol) composites Macromol. 43 2357-63

[54] Dreyer D R, Park S, Bielawski C W and Ruoff R S 2010 The chemistry of graphene oxide Chem. Soc. Rev. 39 228-40

[55] Cozzolino C A, Cerri G, Brundu A and Farris S 2014 Microfibrillated cellulose (MFC): pullulan bionanocomposite films Cellulose 21 4323-35 